\title{
La problemática de lo impresentable: la lectura de Jean François Lyotard del expresionismo abstracto americano
}

\section{The Problem of the Unpresentable: Jean François Lyotard and American Abstract Expressionism}

\author{
Alberto Santamaría \\ Departamento de Historia del Arte, Facultad de Bellas Artes, Universidad de \\ Salamanca. Salamanca, España \\ albertosantamaria@usal.es
}

\section{Resumen}

El objetivo de este artículo es analizar la relación entre el pensamiento de Jean François Lyotard y el expresionismo abstracto americano. En primer lugar, estudiaremos las ideas de Lyotard acerca de la estética kantiana. En segundo lugar, nos centraremos en el tema de lo sublime. Finalmente, abordaremos el estudio del concepto de tiempo que determina la conexión entre Lyotard y el expresionismo abstracto.

Palabras clave: Lyotard, sublime, estética, expresionismo abstracto, Barnett Newman.

\begin{abstract}
The aim of this article is to analyze the relationship between the thought of Jean François Lyotard and the american abstract expressionism. Firstly, we will study the ideas of Lyotard about Kantian aesthetics. Secondly, we will focus on the theme of the sublime. Finally, we will tackle the study of the concept of time that determines the connection between Lyotard and abstract expressionism.
\end{abstract}

Keywords: Lyotard, sublime, aesthetics, abstract expressionism, Barnett Newman. 


\section{Reescritura kantiana: sentimiento y moralidad}

El problema del juego teórico entre lo presentable e impresentable, desde sus formulaciones originarias de índole kantiana, y en vínculo directo con la problemática del arte contemporáneo y lo sublime, han movido a gran parte de la filosofía europea -fundamentalmente francesa- en el último tercio de siglo xx. Así, en el prefacio al libro colectivo Du Sublime, Jean Luc Nancy afirmaba que "la cuestión de lo sublime nos es transmitida en tanto que cuestión de la presentación” (8). En este término se juega gran parte de la estética y sus posibilidades. El propio Nancy afirmará, recordando en cierta medida los postulados lyotardianos: "En lo sublime está entonces en juego la presentación misma: no alguna cosa por presentar o por representar, ni alguna cosa impresentable (ni lo impresentable de la cosa en general), y tampoco el hecho de que eso se presente a un sujeto y por un sujeto (la representación), sino el hecho de que eso (se) presenta, y como eso (se) presenta" ("La ofrenda sublime" 132). En este nivel de vinculación directa con los diferentes motivos y estrategias de la representación contemporánea (posmoderna) se sitúa esta posibilidad de reescritura de lo sublime.

Será, sin embrago, Jean François Lyotard quien ahonde con mayor profundidad en esta problemática. Para Lyotard, la cuestión de lo impresentable, y por tanto la de lo sublime, es "la única cuestión digna de los desafíos de la vida y del pensamiento en el siglo próximo” (Lyotard, Lo inhumano 131). En cualquier caso, como muy bien ha estudiado Paul Crowther, para establecer un análisis de los modos de reescritura de lo sublime lyotardiano es necesario tomar como esquema arquitectónico previo los modos kantianos de lo sublime, pues Lyotard basa su uso -no estudio- de lo sublime en las formulaciones fundamentalmente kantianas -y también burkeanas- de lo sublime.

Sobre esta base, y después de varios años estudiando el tema, Lyotard entabla un profuso y constructivo diálogo con el marco reducido de la estética de lo sublime kantiana. En las Leçons sur l'analytique du sublime -texto del cual partiremos para derivar finalmente en su lectura del expresionismo abstracto- se centra en el estudio y comentario de los parágrafos del 23 al 29 de la Crítica del juicio, en que Kant se ocupa específicamente de la analítica de lo sublime. En este libro es donde Lyotard desarrolla parte de su técnica de reescritura. No sigue de un modo exacto y preciso la línea argumental kantiana, sino que va reactualizando temas, estableciendo nuevos movimientos sobre la base de esa analítica.

El objeto de esta tercera crítica kantiana es la llamada facultad de juzgar, cuyos poderes en principio son valorar lo bello y lo sublime. Ambos pertenecen a la reflexión estética, aunque se establezcan necesarias alteraciones y variaciones dentro del mismo marco reflexivo. Así, al comienzo de la analítica de lo sublime, Kant señalaba ya la ingeniería básica sobre la que se fundamentaría la ulterior explicitación teórica: 
Lo bello tiene de común con lo sublime que ambos placen por sí mismos. Además, ninguno de los dos presupone un juicio sensible determinante, sino un juicio de reflexión. [...] Pero hay también entre ambos diferencias considerables, que están a la vista. Lo bello de la naturaleza se refiere al objeto, que consiste en su limitación; lo sublime, al contrario, puede encontrarse en un objeto sin forma (Kant 183).

De este modo, Kant delinea los espacios fundacionales de la comprensión estética. Dentro de este marco, lo bello será tomado como la exposición de un concepto indeterminado del entendimiento, mientras que lo sublime se tomará como la exposición de un concepto semejante de la razón.

En función de estas vías iniciales, Lyotard advierte que la analítica de lo sublime es fundamentalmente negativa, dado que no reclama la presencia de una forma ni de la imaginación. Hay una inadecuación en su formación entre la imaginación -que tiende a progresar hacia lo infinito- y la razón -cuya pretensión es la totalidad absoluta-: "Enfrentada con objetos que son demasiado grandes de acuerdo con su magnitud y demasiado violentos de acuerdo con su poder, la mente experimenta sus propias limitaciones" (Lyotard, Peregrinaciones 65). En este sentido, el concepto de límite, de su superación, en tanto que desbordamiento de lo dado en la forma, suele traerse al marco interpretativo de lo sublime. En palabras de Lyotard, "el sentimiento de lo sublime no es más que, desde este aspecto, la impresión de un pensamiento, de este sordo deseo de ilimitación" (Lyotard, Leçons sur 75). Lo sublime podría entenderse como una situación límite en la que se pretende pensar un objeto no esquematizable como totalidad.

A nivel de las diferencias esenciales, es fácil observar cómo el gusto estético relativo a lo bello es inducido por la forma, mientras que el sentimiento de lo sublime se relaciona directamente con un objeto sin forma. La forma implica limitación, y aquí se juega -ya se ha dicho- en el terreno de la ilimitación. El sentimiento de lo bello guarda relación directa con el entendimiento, mientras que lo sublime establece su vínculo -y sustento- con la razón. En este marco, sin embargo, hay otra semejanza en cuanto que ninguno de los dos sentimientos es pensado -ni pueden serlo- mediante conceptos. Lo sublime se vincula con la razón porque no hay de él presentación posible: Dios, alma, libertad, ideas de razón, en fin, no son objetos empíricos que puedan estar presentes. Por el contrario, lo bello es una forma presentable. El propio Kant así lo expone: "Solo podemos decir que el objeto es propio para exponer una sublimidad que puede encontrarse en el espíritu, pues lo propiamente sublime no puede estar encerrado en forma sensible alguna, sino que se refiere tan sólo a ideas de la razón, que, aunque ninguna exposición adecuada de ellas sea posible, son puestas en movimiento y traídas al espíritu" (Kant 185). Este es el modo en el que actúa y se muestra lo sublime kantiano, que juega al nivel de la (im)presentación y de la fractura de todo límite, y en este modo se diferencia de lo bello. Lyotard sostiene que esta diferencia 
entre lo bello y lo sublime es de tipo trascendental y no meramente de énfasis. Jean-Luc Nancy, por su parte, vendrá a destacar esta modalidad del juego de la presentación, afirmando que "lo bello y lo sublime tienen en común, para Kant, el tener que ver con la presentación, y con ella sola. En el uno y en el otro no se juega otra cosa que el juego de la presentación, sin objeto representado" ("La ofrenda sublime" 120).

A diferencia de lo bello, el sentimiento de lo sublime es en realidad una emoción, algo que Kant pudo observar ya en Burke, cuando este afirmaba -desde un punto de vista psicofisiológico y no trascendental- que lo sublime "produce la emoción más fuerte que la mente es capaz de sentir" (Burke 29). Mientras que el placer de lo bello es positivo, la emoción de lo sublime tiene cierta ambivalencia, en función de su aspecto negativo. Así, sostiene Kant que "la satisfacción en lo sublime merece llamarse no tanto placer positivo como, mejor, admiración o respeto, es decir, placer negativo" (Kant 184). El sentimiento de lo sublime "no es un mero placer como el gusto -es una mezcla de placer y dolor. La entrada del sufrimiento en el sentimiento estético debe entenderse como una sombra proyectada sobre la obra imaginativa por una Idea de la razón" (Kant 184). Se trata, sin duda, de un sentimiento contradictorio en el que entran en juego el placer y el dolor: dolor que nace de la impotencia de la imaginación para aprehender otra cosa que la cantidad limitada y placer que proviene de la aprehensión, por parte de la razón, de la idea de la cantidad ilimitada. Según Kant:

El sentimiento de lo sublime es, pues, un sentimiento de dolor que nace de la inadecuación de la imaginación, en la apreciación estética de las magnitudes, con la apreciación mediante la razón; y es, al mismo tiempo, un placer despertado por la concordancia que tiene justamente ese juicio de inadecuación de la mayor facultad sensible con ideas de la razón (199-200).

En función del sentimiento de lo sublime, ya Addison, y anteriormente Longino, mostraban las vistas del mar embravecido, el desierto, la furia, como esquemas o ejemplos de lo sublime, y Kant lo hará igualmente, pero señalará constantemente la presencia de lo "subjetivo" como elemento vertebrador:

no se puede llamar sublime al amplio océano en irritada tormenta. Su aspecto es terrible, y hay que tener el espíritu ya ocupado con ideas de varias clases para ser determinado, por una intuición semejante, a un sentimiento que él mismo es sublime, viéndose el espíritu estimulado a dejar la sensibilidad y a ocuparse con ideas que encierran una finalidad más elevada (185).

Y unas líneas más abajo: "se ha de buscar lo sublime, no en las cosas de la naturaleza, sino solamente en nuestras ideas" (190), aunque posteriormente aclara que esa naturaleza es capaz de provocar -es símbolo de- el sentimiento sublime. Así, afirma que "llamamos gustosos sublimes esos objetos porque elevan las facultades del alma por encima de su término medio ordinario y nos hacen descubrir en nosotros una facultad de resistencia de una especie totalmente distinta, que nos da valor para poder 
medirnos con el todo-poder aparente de la naturaleza" (204). Provoca lo que Derrida denominó sobre-elevación.

En principio, destaca Kant la imposibilidad de mostrar lo sublime en el arte, algo que no tanto en Lyotard, sino en la reescritura derridiana, será fundamental. La posterior simbolización dará posibilidades al arte y fundamentalmente al arte abstracto, según Lyotard. Este es el marco en que la visión derridiana choca -y en ocasiones entronca- con la reescritura lyotardiana. Según Kant, "hay que mostrar lo sublime, no en los productos del arte [...], donde un fin humano determina, tanto la forma como la magnitud [...] sino en la naturaleza bruta" (194). Sobre esta naturaleza bruta desarrolla Derrida su reescritura de la analítica de lo sublime, centrándose en el problema del coloso como escenificación kantiana de lo sublime. Esta llamada naturaleza bruta "sobre la cual habría que 'mostrar' (aufzeigen) la sobre-elevación sublime será bruta porque no ofrecerá ningún 'atractivo' (Reiz) y no provocará ninguna emoción de temor ante un peligro. Pero deberá implicar 'grandezas', grandezas que sin embargo desafían la medida" (Derrida 132). El arte no podría alcanzar este campo. Kant sitúa lo colosal como ocasión de lo sublime. Es aquí donde, comentado brevemente, Derrida parece apuntar una determinada paradoja: Kant se fija en lo colosal para definir lo sublime, pero al mismo tiempo insiste en que se trata de la presentación de algo que, sin embargo, es impresentable. Se toma el coloso como símbolo presente de algo que en realidad es impresentable. Es posible así apuntar la idea de una recreación de determinado lenguaje teológico.

De un modo u otro, la formulación de una introyección que recrea a partir de una recepción es evidente en la propuesta kantiana. Kant sostiene que se obliga al sujeto - y con ello se incide en el hecho de la imposibilidad de la (re)presentación - "a pensar subjetivamente la naturaleza misma en su totalidad, como exposición de algo suprasensible, sin poder realizar objetivamente esa exposición" (Kant 213). El sentimiento de lo sublime es la experiencia límite kantiana de la totalidad; es la vivencia de la finitud, de la limitación del individuo y de su infinitud como ser humano.

En definitiva, escribe Lyotard en su análisis de Kant, el sentimiento de lo sublime constituye "una emoción violenta y ambivalente que el pensamiento experimenta con ocasión de lo 'sin forma"' (Lyotard, Leçons sur 123). En La posmodernidad (explicada a los niños) describía así la formulación kantiana: “Tenemos la Idea del mundo (la totalidad de lo que es), pero no tenemos la capacidad de mostrar un ejemplo de ella. [...] Podemos concebir lo absolutamente grande, lo absolutamente poderoso, pero cualquier presentación de un objeto destinado a 'hacer ver' esta magnitud o esta potencia absolutas se nos aparece como dolorosamente insuficiente" (21).

Avanzando en su estudio, Lyotard introduce el tema del diferendo: "El diferendo entre lo finito y lo infinito no se experimenta plenamente en el pensamiento más que si el pensamiento finito (el de la forma) se sustrae a la finalidad que es la suya para tratar de ponerse a la medida de la otra parte. No hay diferendo sin este gesto" (21). Aquí sólo puede haber un signo de una presencia que, sin embargo, no es nunca una 
presentación. Por eso se puede concluir que lo absoluto se muestra solo de forma negativa. Lo absoluto es impresentable. Lo sublime presenta "inadecuadamente lo infinito en lo finito y lo delimita violentamente alli’” (Derrida 140). El diferendo no implica la incomprensión de una parte con respecto a la otra. Exige, en cambio, comprensión del idioma del otro, "aunque no se puede satisfacer esta demanda con los medios de su propio idioma" (Lyotard, Leçons sur 187). De este modo, toda posible insinuación de lo absoluto, de lo impresentable -la pintura moderna, según Lyotard, es un ejemplo- se efectuará -no puede ser de otro modo- mediante la ausencia de forma. Kant cita a este respecto el Éxodo, según el cual no se podrán esculpir imágenes de Dios. Se prohíbe, de esta forma, cualquier presentación formal -figurativa, expresiva, positiva- de lo absoluto. Este no se podrá implica, bajo la óptica lyotardiana, el principal campo de reescritura de lo sublime, al postular en este marco la posibilidad de una presentación negativa.

Desde aquí, desde este ámbito de reelaboración de ciertos niveles insertos en la reflexión kantiana, expandidos hacia otras esferas, propone un sublime estético en la pintura moderna. Un sublime aún nostálgico, dirá; previo al sublime contemporáneo (posmoderno). En este sentido es que pretende Lyotard su reescritura de la modernidad; este es un caso de esa reescritura. "No hay mucho más que agregar a estas observaciones para esbozar una estética de la pintura sublime: como pintura, esta estética 'presentará sin duda algo, pero lo hará negativamente, evitará pues la figuración o la representación, será 'blanca' como un cuadrado de Malevich, hará ver en la medida en que prohíbe ver, procurará placer dando pena" (La posmodernidad 185). Se interroga acerca de si desde Kant y el Romanticismo, la literatura y el arte, con su sumisión a las formas, puede testimoniar lo absoluto. En todo caso, parece que lo bello deja de ser su objeto. No se trata de una revolución sino de un movimiento lento, pausado, incluso incierto. De acuerdo con Lyotard, hay un claro desarrollo, una evolución que es una mutación o inversión en el interés por insinuar lo absoluto, en que figuras como Longino, Boileau, Burke, Kant, el Romanticismo, la vanguardia, son los diferentes nódulos de una evolución/inversión.

El entusiasmo es otro marco de análisis, y otro motivo importante (Lyotard, $E l$ entusiasmo 68). Dice Kant: "La idea del bien con emoción se llama entusiasmo. [...] Estéticamente, empero, es el entusiasmo sublime, porque es una tensión de las fuerzas por ideas que dan al espíritu una impulsión que opera mucho más fuerte y duraderamente que el esfuerzo por medio de representaciones sensibles" (Kant 218). Por su parte, Lyotard apunta: “Toda emoción, todo estado subjetivo del pensamiento puede dar paso a lo sublime, la cólera, la desesperación, la admiración e incluso la falta de afecto" (Lyotard, Leçons sur 189). Lo sublime difiere más por la cantidad de energía que por la cualidad de los sentimientos implicados. Desde Burke, "lo sublime ya no es una cuestión de elevación [...] sino de intensificación" (Lyotard, Lo inhumano 104). La desesperación abatida no es sublime, pero sí lo es la desesperación rebelde, la justa indignación, la energía de la desesperación: "Esta energía es lo que da cualidad afectiva singular, su valor sublime, su nobleza" (Lyotard, Leçons sur 190). 
En cualquier caso, la idea estética, según dibuja Lyotard, se caracteriza por su "nomostración”, es decir, por la imposibilidad de ofrecer una exposición plena y efectiva; mientras que la idea racional es indemostrable. Se establece no una identidad entre ética y estética, sino una analogía. El hecho de que se hable de la inmostrabilidad de la idea estética indica, solamente, que es un símbolo de la indemostrabilidad de la idea racional. Igualmente, lo sublime solo puede establecer su universalización mediatamente, esto es, a través de una idea de la razón. (Mientras, la moralidad implica la presencia inmediata e incondicional ante el pensamiento de la idea de la libertad). La exigencia de universalidad se experimenta por el respeto, el cual en sí mismo no es placer ni dolor, no implica atracción-repulsión. Por eso, el placer que acompaña a lo sublime no es directamente ético, sino un placer contemplativo; y así el "el placer como parte del sentimiento de lo sublime solo puede comunicarse universalmente si ya presupone otro sentimiento, el de su destino suprasensible" (Lyotard, Leçons sur 272). Lo sublime, entonces, "tiende a una 'satisfacción exultante' que procede de la idea de lo absoluto; pero solo el pensamiento razonador puede representar este objeto impresentable, que es propiamente una Idea" (271).

Aunque en la bibliografía e historia literaria del propio Lyotard, el texto sobre la analítica de lo sublime de Kant es tardío, es necesario atender primeramente esta reescritura, esta perlaboración que parte del propio texto kantiano y que con anterioridad había sido reconectado en la amplitud de su obra. Empezar así por esta revisión general de Kant desde Lyotard es útil para derivar hacia la visión personal y el uso teórico amplio del tema que lleva a cabo el filósofo francés a lo largo de la década de los ochenta. Lyotard considerará esta cuestión clave para entender los problemas del arte $-y$ por tanto de la estética y de la sensibilidad en general- en el final del siglo Xx y comienzo del siglo xxI, una vez que las formas nostálgicas, metafísicas del arte y la filosofía han caído como modelos obsoletos, en favor de una nueva serie de posibilidades estéticas, teóricas y creativas. Toma como figuras teóricas clave primero a Burke y luego a Kant, estableciendo un vínculo preciso y una estrecha correlación entre ambos. Lyotard entonces observa en lo sublime la posibilidad explicativa de la contemporaneidad, en lo sublime reconectado (posmoderno), es decir, invertido. Este es su modo de inversión.

\section{Lo sublime: posibilidad interpretativa}

A finales de la década de los ochenta, en la que es posible denominar como su biografía intelectual, Pereginaciones, Lyotard apunta brevemente alguno de los motivos que le llevan al tema de lo sublime, hallando en él una rica variedad de posibilidades teóricas.

Entroncando con lo ya dicho, estética y práctica parecen en ocasiones mostrar cierta similitud; sin embargo, "la asignación de una similitud de estatus -esgrime Lyotard- tal a las comunidades estética y práctica se debe desafiar como un engaño" 
(Peregrinaciones 63). En el tercer capítulo de este libro, Lyotard trabaja por establecer y estipular los modos de diferenciación esencial entre ambas esferas y ambas comunidades, para lo cual hunde igualmente sus raíces en el terreno kantiano. La diferencia crucial es que el placer estético "no tiene nada que ver con la satisfacción de ninguna necesidad en absoluto, ya sea empírica, es decir, 'patológica', o trascendental, esto es, ética" (Lyotard, Peregrinaciones 59). Por su parte, cuando se habla en un sentido práctico se entabla una referencia directa a un acontecimiento que se enfrenta a una voluntad material involucrada en necesidades, valores, motivaciones, etcétera. No surge ningún placer de la ley y de la obligación.

El modo en el que Lyotard emprende su camino hacia lo sublime parte del hecho de una ruptura con determinadas concepciones concernientes a lo bello, la comunidad, el consenso, el juicio, la delimitación frente a lo ético y lo político. Volviendo al tema estética y política, dentro de unos límites "kantianamente lyotardianos", que son los que le llevan a lo sublime, el filósofo francés analiza la realidad -y la teoría- política y observa -recordando quizá su enfrentamiento con Habermas- que, en el terreno de la política, de la práctica -y quién sabe en el de la estética-, sigue siendo no solo posible sino necesaria una serie de argumentaciones acerca del modo de evaluación del caso que se juzga. Incluso se puede ir más lejos afirmando que cuanto más numerosas sean las disputas, las discusiones, los intentos dialécticos y retóricos para poder entablar un proceso de convencimiento y persuasión del otro, "cuanto más desarrollada esté la responsabilidad hacia la idea moral, tanto más madura será lo que Kant denomina la 'cultura de la voluntad"' (Lyotard, Peregrinaciones 63). Hay en el mundo contemporáneo, según denuncia Lyotard, un proceso de estructuración y encajonamiento dentro de procesos deliberativos y judicativos de diversas situaciones y modos que se habían considerado hasta entonces como naturales, e incluso propias del instinto o del hábito. Estos procesos de deliberación, de consenso y discusión provocan en muchos casos una extensión hacia terrenos no cautivables en principio por esos procesos retóricos y dialécticos.

En su conferencia pronunciada en la Universidad de California, expone un ejemplo preciso de la realidad norteamericana -y por tanto mundial-: "En el campo político, amenazado como está por las necesidades urgentes, puede detectarse un signo de ese progreso en el auge que los principios republicanos están cobrando en la mentalidad general" (Peregrinaciones 64). Pero ¿qué tipo o forma de progreso se da en el marco estético? ¿Se podría hablar de un proceso/progreso de consenso y diálogo tal en el terreno estético artístico? Más adelante, señala que, por el contrario, parece que no hay un progreso de este tipo en el marco de la historia del arte. Es irrelevante una discusión acerca de si hay más belleza en la Torre de Pisa o en la Torre Eiffel. Parece como si la belleza no dejase posibilidad alguna al progreso o a un determinado progreso. No podría haber, así, nada parecido a un progreso estético. "Salvo..., salvo ¿qué? Salvo si la belleza y la noción del gusto vinculada a ella no fueran la única manera de responder ante los acontecimientos estéticos" (Peregrinaciones 
64). Es decir, salvo si se desarrollase un modo diferente de juzgar, un juicio diferenciado en su estructura y sus extensiones, un ámbito no determinado o sometido a ese proceso de consenso. De este modo pasa Lyotard al estudio de lo sublime más allá de las comunidades y consensos al nivel de lo bello y lo ético. Lo sublime es la posibilidad tanto para el filósofo como para el artista. A partir de la formulación general de lo sublime, de su bifurcación y conflicto entre placer y dolor, imaginación y razón, etcétera, sería posible esbozar una extraña estética donde el elemento que da base al sentimiento estético ya no sea la libre síntesis de formas llevada a cabo por la imaginación, sino el fracaso mismo a la hora de sintetizar. Este fracaso, esta carencia en lo referente a la síntesis, a la facultad, corresponde a nombres como lo informe. Esto implica, según Lyotard, no que el objeto dado para desatar el sentimiento deba ser monstruoso, sino que la forma, como delimitación objetual, ya no es el fin, el objetivo, de ese sentimiento estético.

Con la estética de lo sublime es posible, además, argumentar un tipo de progreso en la historia humana que no sea solo el construido y formado por los elementos tecnológicos y científicos. Ciertamente, así no se habla de un "progreso de lo hermoso, del gusto de la belleza, sino de la responsabilidad con respecto a las ideas de la razón conforme éstas son 'presentadas' negativamente en la amorfidad de una situación concreta que se pudiera dar" (Peregrinaciones 66).

\section{Extensiones artísticas: lo sublime y lo impresentable}

En la lectura que Lyotard realiza de los modos y acontecimientos en los que ha caído el mundo contemporáneo, regido por valores de programación, predicción, eficiencia, seguridad, cálculo -raras herencias modernas- observa un amplio triunfo del llamado por Kant juicio determinante: "El Juicio determinante bajo leyes universales trascendentales que da al entendimiento no hace más que subsumir; la ley le es presentada a priori, y no tiene necesidad, por lo tanto, de pensar por sí mismo en una ley" (Kant 105). A pesar de ello, Lyotard señala la posibilidad -y la necesidad-, sin duda, de acceso a otros juegos de discurso donde la pretensión de establecer una normalización previa, una estructura de modelos judicativos o la simple pretensión de dar una explicación, es irrelevante e incluso contraproducente. En particular, dice Lyotard, este es el caso de los juicios reflexionantes. Sobre este tipo de juicios, que entroncan perfectamente con el "ideario" lyotardiano, escribe Kant:

El Juicio reflexionante puede, pues, tan solo darse a sí mismo, como ley, un principio semejante, trascendental, y no tomarlo de otra parte (pues entonces sería Juicio determinante) ni prescribirlo a la naturaleza, porque la reflexión sobre las leyes de la naturaleza se rige según la naturaleza, y esta no se rige según las condiciones según las cuales nosotros tratamos de adquirir de ella un concepto que, en relación a esas, es totalmente contingente (106). 
Lyotard emprende a través de este carácter no determinante el camino hacia lo sublime y el arte contemporáneo, observando en la realidad artística más actual una sublimidad no sujeta a nostalgias ni misticismos. En este marco estético reflexionante, no hay concepto alguno o finalidad externa; tampoco interés empírico o ético involucrado en la recepción por parte de la imaginación de sensaciones externas.

Aproximadamente será así cómo, una vez leída la formulación kantiana, Lyotard establezca su reescritura de los motivos sublimes en el ámbito contemporáneo:

Un artista, un escritor posmoderno, están en la situación de un filósofo: el texto que escriben, la obra que llevan a cabo, en principio, no están gobernados por reglas ya establecidas, y no pueden ser juzgados por medio de un juicio determinante, por la aplicación a este texto, a esta obra, de categorías conocidas. Estas reglas y estas categorías son lo que la obra investiga. El artista y el escritor trabajan sin reglas y para establecer las reglas de aquello que habrá sido hecho (La posmodernidad 25).

Este es el juicio reflexionante que impone como base Lyotard a la hora de abordar y redibujar lo sublime (kantiano) en el arte contemporáneo, y es así como Barnett Newman entra a formar parte del marco teórico lyotardiano. Es fácil observar a partir de este fragmento los modos que le interesan a Lyotard de la reflexión kantiana: establece una reescritura de los modos estéticos. Transita desde el punto de partida del juicio kantiano, centrado en el espectador, en el crítico, hacia un espacio cuyo origen es la creación, el artista mismo. En el primer caso, se juzga según la naturaleza, desde sí mismo, mientras que, en el segundo momento de reescritura, se crea sin reglas previas precisas. Hay un paso, una concreta inversión.

El artista, opina Lyotard -y esto se verá perfectamente a través de Newman-, se da a sí mismo la norma. No parte de una ley previa, de una cultura que delinea unas determinadas formalizaciones creativas. Por ello estas obras, así vistas, tienen carácter de acontecimiento, de gesto que da pie a una amplia intensidad creativa bajo la formulación de un ahora de la presentación.

Aunque Lyotard tiende a afirmar, a través de algún ejemplo y en contadas ocasiones, que su construcción reflexiva alrededor de lo sublime es aplicable igualmente a la literatura, es sin duda evidente que su teoría se desarrolla en estrecha conexión con las artes visuales, fundamentalmente, y en particular con la pintura. De este modo, sus primeras especulaciones rondan acerca de una defensa de la pintura de vanguardia. Y una de sus primeras referencias como punto clave de ruptura en la historia de la pintura es Cézanne. Este pintor francés supone para Lyotard la auténtica ruptura con el espacio pictórico moderno que había comenzado en el Quattrocento italiano. Es entre los años 1895 y 1938 cuando se va operando esta revolución pictórica. El espacio moderno, vigente desde el Quattrocento, se caracteriza por el hecho clave de que la obra de arte cumple fundamentalmente una función de representación. En este sentido, la función de la pintura ha sido documentar los diferentes órdenes 
establecidos a nivel social, político y religioso, a través, precisamente, de una ley de perspectiva que intenta que la audiencia, los espectadores, se identifiquen con ese orden representado y con la maestría técnica del artista. Dice Lyotard:

La pintura conquistó sus cartas de nobleza, se la incluyó entre las Bellas Artes y se le reconocieron derechos casi principescos durante el Quattrocento. Desde entonces y a lo largo de varios siglos, contribuyó por su parte al cumplimiento del programa metafísico y político de organización de lo visual y lo social. [...] Ubicados en la escena perspectivista, los componentes de esas comunidades, narrativas, urbanísticas, arquitectónicas, religiosas, éticas, se ordenan ante el ojo del pintor gracias a la costruzione legittima. [...], estas referencias brindaban a todos los miembros de la comunidad la misma posibilidad de identificar su pertenencia a ese universo, como si fueran el monarca o el pintor (Lo inhumano 123-4).

Se observa, claramente, el modo en el que la pintura jugaba un papel político y social a través de un modelo evidente de simbolización. La pintura mostraba un símbolo, una sociedad, y el sujeto observador se identificaba con esa estructura mostrada, adhiriendo plenamente a la comunidad. Esta modalidad de representación es la que será cuestionada en el marco contemporáneo. Es con Cézanne, en principio, que se operará un cambio radical, dado que un fuerte principio de desrepresentación atraviesa toda su obra, un principio que la centra y estructura. El cuadro deja de ser símbolo de otra cosa y adquiere valor por sí mismo. El mensaje, la moraleja, queda a un lado, sin importancia.

Cézanne es el principio, pero el centro hacia el cual se desplaza su interés pictórico en la década de los ochenta es el pintor norteamericano Barnett Newman. Como se verá, ello se debe fundamentalmente a dos motivos: su obra y sus textos. Pero antes de desarrollar la obsesión de Lyotard por Newman, es necesario observar cómo llega teóricamente a él y cómo sitúa lo que llamará nuevo sublime o sublime inmanente.

El año 1982 aparece un texto de Lyotard en la revista Artforum bajo el título original de "Presenting the unpresentable: the sublime", que posteriormente formaría parte del libro Lo inhumano. Es en este trabajo donde por vez primera atisba de modo concreto las posibilidades de lo sublime en relación directa con el arte contemporáneo. Del mismo modo, en ese año está fechado también el texto "Respuesta a la pregunta: ¿qué es lo posmoderno?”, donde da forma inicial y general a esa inquietud interpretativa.

El primero de los textos tiene como eje importancia rupturista de la fotografía en el siglo xx; su impacto sobre el resto de las artes, fundamentalmente sobre la pintura de vanguardia. Con respecto a la pintura, por ejemplo, la fotografía supone la crisis de ese antiguo estatus documentalista y representativo antes mencionado. La pintura se ve obligada a investigar nuevos territorios. O visto de otro modo, la fotografía supone la consumación del ideario pictórico del Quattrocento: "La fotografía lleva a su 
consumación ese programa de puesta en orden metapolítico de lo visual y lo social. Lo consuma en los dos sentidos de la palabra: lo cumple y le pone fin" (Lyotard, Lo inhumano 124). Así, de este modo se cuestiona y se pregunta por el arte y por su posibilidad en el ámbito contemporáneo.

La fotografía desplaza territorialmente a la pintura, hace "imposible" su oficio, una imposibilidad que proviene "del mundo tecnocientífico del capitalismo industrial y posindustrial. Ese mundo necesita la fotografía y casi no necesita la pintura” (123). La fotografía ocupará así el lugar antiguo de la pintura como valor representativo e identificativo; una fotografía cuyo desarrollo apunta, verdaderamente, hacia una total transformación de la sensibilidad estética. El hecho es evidente, el desarrollo técnico de la fotografía implica una nueva distribución de papeles en el ámbito originario del hacer creativo -y también receptivo-. De este modo, por un lado, el desarrollo técnico y, por el otro, la popularización de la propia máquina fotográfica, van afectado gradualmente a la imaginería consecuente -y cotidiana- del quehacer pictórico. "Con un solo clic el más modesto de los ciudadanos, en calidad de aficionado y turista, hace su cuadro, organiza su espacio de identificación, enriquece su memoria cultural, hace compartir sus prospecciones" (124). Si anteriormente este mecanismo documentalista, propio de la pintura, exigía una determinada nobleza en el oficio; es decir, el desarrollo de un aprendizaje en el taller durante años, un fino desarrollo de la experiencia visual, un posicionamiento y movimiento ante el lienzo, un cierto don innato, etcétera; ahora, en la fotografía, estas determinaciones creativas, "se programan en la máquina fotográfica gracias a finas capacidades ópticas, químicas, mecánicas, electrónicas. Al aficionado le queda la elección del ajuste y el tema” (124). Pintores como Courbet o Manet, señala Lyotard, aún habían pretendido cierto afán documentalista, pero pronto fueron derrotados. No es posible entablar competencia alguna: la formación profesional del pintor es mucho más lenta, los materiales tienen un coste más alto, el tiempo de producción de un cuadro es mucho mayor y, junto con ello, el coste del mantenimiento; globalmente no es posible establecer un serio proceso competitivo al mismo nivel (imitativo).

El arte, la pintura, parece así acorralada, superada por su propia obsesión representativa. Pero en este inicio de siglo xx, junto con la fotografía que desplaza a la pintura, surge paulatinamente - pero con fuerza-, la posibilidad de un desvío (desafío) con respecto, precisamente, al soporte artístico, es decir: el ready made industrial y la figura de Duchamp. Escribe Lyotard: "Duchamp llega a la conclusión de que ya no es posible la pintura. Quienes persisten en ella deben afrontar el desafío de la fotografía" (Lo inhumano 125). Para sobrevivir, la pintura ha de reescribir, entonces, su propia ingeniería, provocando así un más allá de la imagen vista. La idea es superar ese mero carácter de representación. Para Lyotard, la nueva pintura es la que se pregunta por el hecho mismo del pintar, no por el tema, no por la forma. La pintura ha de tomar ciertas riendas reflexivas, convertirse propiamente en actividad filosófica y, si quiere superar el escollo de la fotografía, ponerse en la posición del teórico para darse a sí 
misma sus reglas. Es fácil recordar aquí, de nuevo, la reformulación del juicio reflexionante kantiano dentro del ámbito artístico contemporáneo. El hecho fundamental de un juicio que parte de la naturaleza misma se transmuta en un creador que rige su creación desde sí mismo. Esta reescritura es formulada ese mismo año, 1982, en el texto "Respuesta a la pregunta: ¿qué es lo posmoderno?", donde Lyotard señala que la obra que lleva ahora a cabo el artista no está gobernada por reglas ya establecidas. Así, la pintura, en su reconexión, en su nuevo posicionamiento, "tiene por regla, más bien, la búsqueda de esas reglas de formación de las imágenes pictóricas, como la filosofía de las frases filosóficas" (Lo inhumano 125).

Como resultado, esta nueva reorganización de la pintura implica, en principio, un distanciamiento con respecto a las formaciones clásicas y taxonomizadas, históricas y sistemáticas, de la actividad creativa. Esta búsqueda de la regla, esta introyección propuesta como análisis del pintar mismo, superando lo temático-objetivado ahora propio de lo fotográfico, implica un distanciamiento de lo público y una progresiva deshumanización a favor de los fenómenos intrasubjetivos. En este tránsito-desplazamiento de la pintura, la posición del simple espectador, del público, ha de variar, dado que ya no se ve identificado con eso que observa, ya no es esa realidad cotidiana o reconocible en general la que muestra la pintura. El sujeto se siente rechazado y puede hallar en la fotografía -incluso en la fotografía realizada por él mismo- esa "necesidad" de identificación, esa urgencia de reconocimiento. Al respecto, señala Lyotard el posicionamiento de las vanguardias: "Las vanguardias se separan así del público. Este maneja máquinas fotográficas bien reguladas y hojea ilustraciones 'apropiadas' (incluso en el cine). Está convencido de que hay que consumar el programa de la perspectiva artificial y no comprende que se tarde un año en hacer un cuadrado blanco, en no representar nada (como no sea lo que hay de impresentable)" (Lo inhumano 125). Desde aquí abre Lyotard la posibilidad interpretativa del nuevo sublime.

En la investigación lyotardiana, como es fácil atisbar, el auge de la fotografía ocupará el campo abierto por la estética clásica de las imágenes, la estética de lo bello. La fotografía supondrá la posibilidad inmediata, a partir de una programación minuciosa, de la producción de imágenes bellas, no dejando espacio a lo indeterminado. ${ }^{1}$

Ante el hecho irrefrenable de esta imagen técnica de la fotografía, como es evidente, los pintores de las vanguardias deben preguntarse por el hecho mismo de qué es la pintura. De este modo, escribe Lyotard:

Los "pintores modernos" descubren que deben formar imágenes que la foto no puede presentar [...] Descubren que tienen que presentar que hay algo no presentable según la "construcción legítima". Se consagran a trastocar los presuntos

1 Aunque apunte y analice esta idea, Lyotard también es consciente de que en el final del siglo xx el desarrollo artístico de la fotografía abre nuevos horizontes para la investigación creativa, rompe con su estatus meramente documentador, ligado a las reglas de la perspectiva artificial. La fotografía, paulatinamente, "queda liberada de las responsabilidades de identificación ideológica que había heredado de la tradición pictórica y en lo sucesivo también da lugar a las investigaciones" (Lo inhumano 127). 
"datos" visuales a fin de hacer visible el hecho de que el campo visual oculta y exige invisibilidades, que no solo compete al ojo (del príncipe) sino al espíritu (vagabundo) (Lo inhumano 128).

Este es el modo en el que "hacen entrar a la pintura en el campo abierto por la estética de lo sublime" (128). Una estética de lo sublime -que aquí delinea por vez primera y empareja con la pintura- que tiene como característica clave el hecho de lo impresentable y como medio para el artista un reescrito juicio reflexionante.

Esta reconectada estética de lo sublime es, para Lyotard, el mejor vehículo interpretativo de las vanguardias pictóricas en el marco de desarrollo de la técnica en el inicio de siglo xx. En su estudio, la pintura de vanguardia escapa por hipótesis a la estética de lo bello, no busca, en ningún caso ese sensus communis de un placer compartido que analizara Kant. Sus obras no son definibles desde los conceptos meramente de forma y gusto. El público se siente rechazado ante lo informe, ante el carácter no-representativo de las obras. La ingeniería simbólica del arte, de la pintura, esto es, la estructuración de las obras en función de unas determinadas ideas de la razón es desestabilizada, derruida, en favor de una inversión de lo sublime donde el arte el arte abandona esos posicionamientos clásicos -y nostálgicos- de la pintura. "En el mundo tecnocientífico e industrial, no puede haber símbolos estables del bien, lo justo, lo verdadero, el infinito, etcétera" (Lyotard, Lo inhumano 128). De este modo, a la hora de abordar el conflicto entre lo ético y lo estético, lo sublime en su inversión puede mostrarse como posibilidad interpretativa, según el modelo lyotardiano de lo impresentable, donde finalmente no hay un modelo estable, una figura presentable.

Un pintor de vanguardia, ante los diferentes estímulos de la sociedad, el mundo y su propio trabajo, es desbordado por una pregunta: ¿qué es la pintura? A partir de ello, lo que su trabajo pone en juego es la pretensión básica de hacer ver que en lo visible existe lo invisible. Esto invisible, esto impresentable es "lo que es objeto de Idea, y de lo cual no se puede mostrar (presentar) ejemplo, caso, y ni siquiera símbolo. [...] Lo sublime no es un placer, es el placer de un pesar: no se logra presentar lo absoluto y eso significa un displacer, pero sabe que hay que presentarlo" (Lo inhumano 129). En cualquier caso, este sublime apropiado por las vanguardias hunde sus raíces en el vocabulario romántico. Para Lyotard, este modo de retomar lo sublime por parte de las vanguardias supone un doble sentido. Por un lado, las vanguardias pictóricas cumplen el Romanticismo, la modernidad; y por el otro, "son una salida a la nostalgia romántica porque no buscan lo impresentable en lo más lejano, como un origen o fin perdidos, a representar en el tema del cuadro, sino en lo más cercano, la materia misma del trabajo artístico" (Lo inhumano 130).

Este tema de la nostalgia y de lo impresentable dibuja perfectamente las líneas de reinterpretación de lo sublime en el siglo $\mathrm{xx}$, y a su vez señala la diferencia entre un sublime moderno y un sublime posmoderno. Es en este sentido en que entra en juego, completando los postulados de "Presenting the unpresentable: the sublime" 
(1982), otro texto del mismo año: "Respuesta a la pregunta: ¿qué es lo posmoderno?"; ambos deben leerse, sin duda, parejamente. Este es un texto que recuerda, de nuevo, la obsesión de reescritura lyotardiana con respecto a Kant, quien había realizado idéntica pregunta en el marco de la Ilustración. Sin embargo, aquí "lo que queda de ella es el afán de presentar lo impresentable, raíz del sentimiento kantiano de lo sublime. Solo que ahora, al ser retomado por las vanguardias, queda despojado, por una parte, de su utopía humanística consoladora, y, por otra, de su pretensión de unidad última en las ideas de la razón, preconizándose la pluralidad activa de lo diferente" (Molinuevo 205). Este es, pues, el tema, la forma en la cual mueve Lyotard lo sublime. El camino hacia una determinada secularización de lo sublime que se produce paulatinamente desde el marco de la pintura de vanguardias y que tiene su punto crucial en la segunda mitad del siglo xx.

Lyotard dibujará los tres modos generales que tienen su raíz en la analítica de lo sublime. Por un lado, la aformidad o ausencia de forma; por otro lado, la llamada abstracción vacía y, finalmente, la presentación negativa. Estos tres modos se vinculan con lo que el autor llama arte moderno o pintura moderna, que trata de presentar qué hay de impresentable. Pero ¿cómo?: "El propio Kant nos dicta la dirección a seguir llamándolo lo informe, la ausencia de forma, un índice posible de lo impresentable. Dice también de la abstracción vacía que experimenta la imaginación en busca de una presentación del infinito (otro impresentable) que esta abstracción es ella misma como una presentación del infinito, su presentación negativa" (La posmodernidad 25). De este modo, la pintura moderna forma parte de esa estética de lo sublime (nostálgica) que hacer ver en la medida en que prohíbe ver.

Hay un cierto desarrollo (inversión) desde esa pintura moderna, dado que se va paulatinamente menguando los accesos de nostalgia de totalidad. Hay un proceso de disminución de excesos trascendentales, podría decirse, que tiene su eje básico en el Romanticismo. Así, Lyotard sostiene, por ejemplo, que "Baudelaire es aún romántico, pero Joyce lo es poco y Gertrude Stein todavía menos. Füssli o Caspar Friedrich son románticos y Delacroix también. Cézanne lo es menos y Delaunay y Mondrian casi no lo son" (Lo inhumano 130). Sin duda, podría seguir dando nombres hasta llegar a Barnett Newman. Su interés no es otro que alcanzar la modalidad de una sublimidad centrada en lo impresentable y ajena a totalidades, a ideas de la razón.

Desde aquí, distinguirá dos modos de sublimidad. Una denominada melancólica o nostálgica de una presencia y otra que denomina novatio. El propio Lyotard lo describe así:

del lado melancolía, los expresionistas alemanes, y del lado novatio, Braque y Picasso. Del primero, Malevich, Chirico; y del segundo, Lissitsky, Duchamp. El matiz que distingue estos dos modos puede ser ínfimo, a menudo coexisten en la misma obra, casi indiscernibles, y no obstante atestiguan un diferendo en el cual se juega desde hace mucho tiempo -y se jugará- la suerte del pensamiento, entre el disgusto y el ensayo (La posmodernidad 24). 


\section{El fracaso del arte europeo: el caso de Barnett Newman como ejemplo}

En 1948, el pintor norteamericano Barnett Newman publica el escrito “The Sublime is Now" en la revista de Betty Parson Tiger's Eye, en un número monográfico titulado "Six Opinions on What is Sublime in Art". Dos años más tarde, en 1950, presenta la monumental tela Vir heroicus sublimis, una obra de 5,40 x 2,40 metros; una obra monocroma de un rojo intensísimo atravesada por una fina línea que rompe el cuadro. El motivo se repite en varios momentos. Es evidente que el tema de lo sublime se inserta con fuerza en el más amplio sistema del expresionismo abstracto (cf. Santamaría).

En Barnett Newman hay un profundo deseo de divorcio con respecto al arte europeo, más concretamente una necesidad de mostrar el constante fracaso de este arte, sobre todo de las vanguardias. El arte europeo no ha logrado lo sublime, y no lo ha logrado porque se ha sumido en una figurativa y concreta nostalgia de lo absoluto (mediada por una representación objetual). Por otro lado, ha mantenido un vínculo constante con lo bello, un extraño deseo de absoluto a través de la figuración y del contenido. Lo bello se ha mantenido siempre en el cerco de la creación y en el propio contexto de lo sublime.

La obra, según estas formulaciones europeas, parece que ha de decir otra cosa, señalar otro lugar; nunca parece o aparece ella misma, por ella misma. Así, dice Newman: "El esfuerzo de Picasso pudo ser sublime, pero no hay duda de que su obra es una preocupación por la cuestión de la naturaleza de lo bello" (Newman 173). Poco después, apunta el hecho fundamental de lo sublime en su inversión, así como el agotamiento de la vía europea para lograrlo:

El fracaso del arte europeo para lograr lo sublime se debe a su ciego deseo de existir dentro de la realidad objetiva [...] y construir un arte dentro del marco de la plasticidad pura [...]. En otras palabras, el arte moderno, atrapado sin un contenido sublime, era incapaz de crear una nueva imagen sublime e incapaz de separarse de la imaginería renacentista de figuras y objetos (Newman 173).

A Newman le interesa insistir en el hecho del fracaso del arte europeo para lograr lo sublime. A partir de esta concepción newmaniana no es comprensible, según afirma, la confusión de planos - por otro lado, muy europea- entre lo bello y lo sublime. El objetivo del nuevo arte - esta es la óptica propiamente de Newman- no es la búsqueda de la belleza, de la forma (algo europeo), sino alcanzar la idea, lo sublime mediante imágenes sin forma, evidentes por sí mismas de una revelación.

Dos son los objetivos de Newman: separarse del arte europeo y autoafirmar un arte americano independiente del europeo (Ratcliff 215). Dos objetivos que sin duda son sumamente parecidos a los ya mencionados por Emerson en El intelectual americano. Newman es, resumiendo, un seguidor no tanto de la letra, como del espíritu de ruptura emersoniano. Incluso cabe citar un pasaje de Whitman que igualmente dé la pauta de esa necesidad de afirmación y distanciamiento. En una de sus cartas, 
Whitman describe horrorizado los hospitales de guerra y el sufrimiento; es entonces cuando afirma: "Frente a estos ¿qué significan vuestros dramas y poemas, incluso los más antiguos y dolientes? No las viejas y poderosas composiciones griegas, con el hombre que pugna con el destino (y siempre sucumbe), ni Virgilio mostrándole a Dante los moribundos y condenados: acércate a lo que yo estoy viendo aquí y toma parte" (cit. en Loving 33). Acércate a lo que yo estoy viendo aquí, este sería el lema y el lugar a seguir en la tradición romántica americana.

Uno de los elementos clave que es importante destacar de lo afirmado por Newman es la cuestión del contenido, ya que siguiendo implícitamente a Emerson y Whitman él cumple uno de sus principios, crear desde uno mismo: no es necesario un contenido que dé la pauta. De este modo, el final del texto es revelador de la cultura norteamericana de lo sublime, que se separa de la europea en el modo de lograr esa sublimidad. Escribe Newman:

Creo que aquí en América, algunos de nosotros, libres del peso de la cultura europea, estamos encontrando la respuesta, negando completamente que el arte tenga nada que ver con el problema de la belleza y dónde hallarla. La cuestión que se plantea ahora es cómo, si vivimos en una época sin leyendas o mitos que puedan llamarse sublimes, si rehusamos admitir ninguna exaltación de relaciones puras, si rechazamos vivir en lo abstracto, ¿cómo podemos estar creando un arte sublime? (173).

La afirmación es tajante: sin ideas de la razón, sin posibilidad de una trascendencia nostálgica, dónde está lo sublime. La cuestión es emersoniana totalmente -en el sentido trascendentalista de la filosofía estadounidense- y la respuesta lo es quizá aún más, y se sitúa en lo más hondo de lo americano:

Estamos creando imágenes cuya realidad es evidente por sí misma. [...] Nos estamos liberando a nosotros mismos de las cargas de la memoria, asociación, nostalgia, leyenda, mito o cualesquiera que hayan sido los recursos de la pintura europea occidental. En lugar de hacer las catedrales a partir de Cristo, el hombre y la vida, las hacemos a partir de nosotros mismos (Newman 173).

Esta podría ser la declaración de independencia vanguardista entre los dos continentes: una auténtica celebración del yo artístico americano que es en realidad el fin del "yo" pintor clásico, es decir "una idea americana”, en palabras de Willem De Kooning. ${ }^{2}$ La tradición emersoniana, más profunda de lo americano, late en la exposición de ese sublime nuevo. La propiedad que antes reclamaba Emerson renace en las manos de Newman, pero hay algo más: es una propiedad que reclama (delata) un nosotros.

2 Carter Ratcliff lleva su argumentación a un terreno político, señalando que debido a los problemas y acusaciones contra Newman y el grupo, la única salida artística fue la "soledad", el aislamiento abstracto, y lo sublime fue el vehículo conceptual idóneo. 


\section{El yo-americano-pintor: lo sublime y (en) el tiempo}

Cuando Newman se refiere al yo americano pintor, como lugar y origen de la creación nueva de lo sublime, es posible inferir también un nosotros, por ejemplo, al afirmar: "creo que en América, algunos de nosotros". Pero ¿quiénes son esos "nosotros"? Lógicamente, hemos de suponer que los componentes del expresionismo abstracto. Y aquí podemos dar una vuelta de tuerca para concluir.

Aunque pueda parecer extraño, para analizar este tema es clave un texto de José Ortega y Gasset, concretamente "Sobre el punto de vista en las artes", que puede ser la llave para comprender este nosotros de Newman, así como este sublime nuevo, invertido y centrado en el yo afigurativo.

En 1949, un año después de la publicación del texto de Newman, Harold Rosenberg y Samuel Kootz buscaron sugerir un movimiento cohesivo organizando una exposición colectiva titulada The Intrasubjectives, en la que se dieron cita todos esos nosotros a los que aludía Newman, nombres como Rothko, Pollock, Motherwell, Reinhardt, entre otros. El título de la exposición que daba forma y sentido a la exposición estaba tomado de aquel texto de Ortega y Gasset, "Sobre el punto de vista en las artes". En esta obra, Ortega y Gasset traza un punto de vista lineal e histórico a partir del cual equipara la evolución de la pintura con la de la filosofía.

Rosenberg y Kootz abren el catálogo con esta afirmación de Ortega, que resume -sin él pretenderlo- el sentido de la nueva pintura norteamericana y sintetiza los postulados emersonianos: "La ley rectora de las grandes variaciones pictóricas es de una simplicidad inquietante. Primero se pintan cosas; luego, sensaciones; por último, ideas. Esto quiere decir que la atención del artista ha comenzado fijándose en la realidad externa; luego en lo subjetivo; por último, en lo intrasubjetivo. Estas tres estaciones son tres puntos que se hallan en una misma línea" (Ortega y Gasset 207).

En otro momento, Ortega y Gasset desarrolla el tema: "Quedarse en lo subjetivo es imposible. ¿Dónde encontrar algo con qué poder reconstruir el mundo?” (Ortega y Gasset 124). Esta misma pregunta se plantea Emerson una vez lograda la independencia intelectual. La respuesta de Ortega: ese nuevo lugar está en el llamado "contenido de la conciencia", en lo intrasubjetivo. Así lo describe: "a lo que las ideas idean y nuestros pensamientos piensan podrá no corresponder nada real, pero no por eso es meramente subjetivo. Un mundo de alucinación no sería real, pero tampoco dejaría de ser un mundo, un universo objetivo, lleno de sentido y perfección" (Ortega y Gasset). Seguramente esta idea penetró con fuerza en la conciencia de estos pintores.

Si dejamos a un lado los escasos conocimientos de Ortega y Gasset sobre arte americano, y el hecho de que hoy esta visión lineal, greenberiana, está bastante cuestionada, podemos intuir el sentido de ese sublime nuevo como expresión de una interioridad más allá de nostalgias e ideas de la razón. Se trata pues de crear desde sí mismo imágenes poderosas no sujetas a esquemas figurativos, reveladores de un más allá, sino de una imagen sublime sin más, creada desde el contenido de la conciencia 
-es decir, desde el punto de vista del creador- y ante la cual el espectador siente el pavor, el desasosiego directo en su conciencia, sin necesidad de simbolismos.

Es a este nivel, a este segundo momento, por decirlo así, al que trata de responder parcialmente Jean François Lyotard, para quien la obra de Newman da cuenta de un tiempo ahora, irresoluble: "Lo inexpresable no reside en un allá lejos, otro mundo, otro tiempo, sino en esto: que suceda (algo). En la determinación del arte, lo indeterminado, el 'sucede', es el color, el cuadro. [...] Que ahora y aquí haya este cuadro y no más bien nada, eso es lo sublime" (Lo inhumano 98). En otro momento, escribe: "Un cuadro de Newman no tiene como fin hacer ver que la duración excede la conciencia, sino ser él mismo la ocurrencia, el momento que sucede" (86).

La lectura lyotardiana parcela el trabajo de Newman en busca de un marco creativo donde situar sus intereses teóricos en torno a lo sublime (tanto política como artísticamente). Para ello, aísla a Newman de su tradición americana, rompiendo su posible relación con Emerson o Whitman. Sin embargo, la aportación de Lyotard es sumamente sugerente si se lee en función de una interpretación cercana a un modelo de reescritura desde Europa. Es decir, Lyotard indirectamente (inconscientemente) interpreta a Newman haciendo de él una bisagra esencial para nuestro trabajo en el tránsito de lo sublime entre Estados Unidos y Europa (y viceversa); un tránsito lleno de tintes de posmodernidad. Para ello, Lyotard se servirá de Burke y de Kant.

Lyotard, pues, desde una dislectura del texto y la obra newmanianas - utilizando términos de Harold Bloom - nos ayuda a establecer un diálogo aun más directo con Newman y lo sublime (americano). Es decir, habiendo analizado los modelos americanos de sublimidad según los cuales la idea del origen, de la nueva tradición, del ahora fundante, adánico e independiente son el eje de una nueva visión de sí mismos como instante-como acontecimiento de un yo-, podemos acercarnos a las siguientes palabras de Lyotard:

El ahora es uno de los "éxtasis" de la temporalidad analizados desde Agustín y Husserl por un pensamiento que intentó construir el tiempo a partir de la conciencia. El now de Newman, now a secas, es desconocido para la conciencia, que no puede construirlo. Es más bien lo que la desampara, la destituye, lo que aquélla no logra pensar e incluso lo que olvida para constituirse a sí misma. Lo que no llegamos a pensar es que algo sucede. O más bien, y más simplemente: que sucede... No un gran acontecimiento, en el sentido de los medios. Ni siquiera uno pequeño. Sino una ocurrencia (96).

Este ahora sin duda señala ese modelo de afirmación que podemos rastrear desde Emerson y que quizá Lyotard pasa por alto. En cualquier caso, el now denota el modelo de un origen, el punto cero de un yo que acontece, y el cuadro es su realidad frente a Europa. La pregunta de Lyotard tiene un sentido heideggeriano: “ ¿y ahora?”. Este principio y pregunta delata el sentido propio y tensional de lo sublime. De esta manera finaliza Lyotard: "que no suceda nada, que falten las palabras, los colores, las formas o 
los sonidos, que la frase sea la última, que el pan no sea cotidiano. [...] No solo ante la tela o la página en blanco, al 'comienzo' de la obra, sino cada vez que algo se hace esperar y por lo tanto suscita una cuestión, en cada signo de interrogación, en cada ‘ ¿y ahora?"” (97). El problema, ya lo hemos visto, es el mismo: ¿cómo crear o alcanzar lo sublime en un marco (cultura) ajeno a nostalgias, totalidades, mitologías...? Quedar en suspenso parece una respuesta, estar aquí, en tierra de nadie.

\section{Referencias}

Burke, Edmund. Indagación filosófica sobre el origen de nuestras ideas acerca de lo sublime y lo bello. Madrid: Tecnos, 1997. Impreso.

Derrida, Jacques. La verdad en pintura. Barcelona: Paidós, 2001. Impreso.

Kant, Emmanuel. Crítica del juicio. Madrid: Austral, 1977. Impreso.

Loving, Jerome. Walt Whitman. El canto a sí mismo. Barcelona: Paidós, 2002. Impreso. Lyotard, Jean François. Leçons sur l'Analytique du sublime. París: Galilée, 1991. Impreso. ---. Peregrinaciones. Madrid: Cátedra, 1992. Impreso.

---. El entusiasmo. Crítica kantiana de la historia. Barcelona: Gedisa, 1997. Impreso.

---. Lo inhumano. Buenos Aires: Manantial, 1998. Impreso.

---. La posmodernidad (explicada a los niños). Barcelona: Gedisa, 2009. Impreso.

Molinuevo, José Luis. La experiencia estética moderna. Madrid: Síntesis, 1998. Impreso.

Nancy, Jean-Luc, ed. Du Sublime. Paris: Belin, 1988. Impreso.

---. "La ofrenda sublime". Un pensamiento finito. Barcelona: Anthropos, 2002. 115152. Impreso.

Newman, Barnett. “The Sublime is Now”. Selected Writings and Interviews. California: University of California Press, 1992. 170-176. Impreso.

Ortega y Gasset, José. “Sobre el punto de vista en las artes”. La deshumanización del arte y otros ensayos de estética. Madrid: Alianza, 1996. Impreso.

Ratcliff, Carter. "The sublime was then: the art of Barnett Newman". Sticky sublime. Ed. Bill Beckley. Nueva York: Allworth Press, 2001. 213-233. Impreso.

Santamaría, Alberto. El idilio americano. Ensayos sobre la estética de lo sublime. Salamanca: Universidad de Salamanca, 2005. Impreso.

Recibido: 10 junio 2016

Aceptado: 12 julio 2017 